\title{
Cartoneros, espacio público y estrategias de supervivencia: Mar del Plata, Argentina, 1990-2014
}

VERÓNICA PAIUA"

JUAN BANE"

\section{Resumen}

Durante la década de 1990 se implementaron en Argentina políticas neoliberales que incrementaron el desempleo y la pobreza. En ese contexto una parte de la población -que ya era pobre - se empobreció aún más y recurrió a la recolección informal de residuos como estrategia de supervivencia. En esa situación el espacio público se convirtió no sólo en un lugar de tránsito sino de reproducción de las condiciones de vida, y, dado que la actividad se realiza a la vista de todos, debieron implementar "fachadas" para acreditarse frente a los demás. Por ello el objetivo de este artículo es analizar las de interacciones que entablan con otros actores y cómo utilizan el espacio público los recolectores informales en la ciudad de Mar del Plata, una ciudad balnearia e intermedia de la Argentina. Las fuentes y la metodología usadas para realizar la investigación fueron la entrevista en profundidad y la observación, además de periódicos de la Ciudad. Los resultados más importantes versan sobre las técnicas que utilizan para acreditarse frente a sí mismos y frente a los demás.

Palabras claves: Interacción social y pobreza. Espacio público. Pobreza urbana. Cartoneros

\footnotetext{
* Universidad de Buenos Aires (Argentina)

** Universidad Nacional de Mar del Plata (Argentina)
} 


\section{Waste pickers, public space and survival strategies: Mar del Plata, Argentina, 1990-2014}

\section{Abstract}

During the 1990s, neoliberal policies were implemented in Argentina, which increased unemployment and poverty. In this context, part of the poor population became even more impoverished and resorted to informal waste collection as a survival strategy. In this situation, public space became not only a space for circulation, but also one for reproduction of living conditions, and, since the activity is carried out in full view of all, they had to set up "façades" so that to get recognition from others. Therefore, the aim of this paper is to analyze the interactions between these individuals and other actors, and how these waste pickers use public space in the city of Mar del Plata, an intermediate seaside city in Argentina. The research was conducted drawing on in-depth interview and observation, and also on City newspapers. The major findings concern the techniques they use to gain self-esteem and recognition from others.

Keywords: Social interaction and poverty - public space - urban-poverty pickers

\section{Introducción}

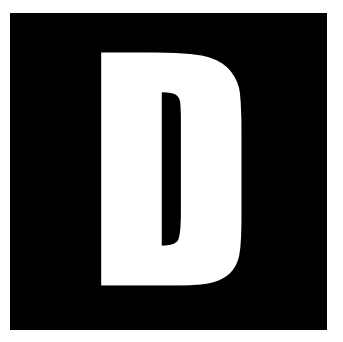

urante la década de 1990, se implementaron en Argentina políticas de perfil neoliberal que implicaron un quiebre en la estructura del estado de bienestar. En dicha etapa se privatizaron las empresas públicas de servicios (luz, gas, agua, etc), la red de transporte ferroviario y se derivó buena parte del sistema previsional de jubilaciones y pensiones al sector privado. Paralelamente, se impulsó la apertura de las importaciones y se dispuso la paridad cambiaria entre el peso y el dólar. Hacia fines de la década del 90, este modelo entró en crisis y se hicieron evidentes las consecuencias sociales de estas políticas. A partir de mayo de 1994, la tasa de desocupación superó los dos dígitos y alcanzó el 18,4\%, en mayo de 1995 y el 21,5\% durante el año 2001 (Beccaria, 2001). Si bien desde 
el año 2003 se modificó sustancialmente la orientación de las políticas económicas y sociales y, si bien se ha revertido la situación crítica, aún quedan consecuencias sociales de dichas políticas, dado que aún hay sectores poblacionales sin empleo y/o en estado de vulnerabilidad.

Si bien esta situación es visible en todas las ciudades del país, existen algunas de rango intermedio ${ }^{1}$ que han sufrido con mayor fuerza el impacto de la crisis. Tal es el caso de Mar del Plata, ciudad balnearia ubicada en la zona sur de la provincia de Buenos Aires. Fundada en el año 1874, sus actividades laborales más importantes son las relacionadas con el sector terciario, tales como la actividad inmobiliaria, el comercio, la hotelería y los restaurantes (75\%), la actividad portuaria y la industria textil. Debido a su condición de ciudad balnearia, buena parte de las actividades comerciales y de servicios se relacionan con el turismo y presentan un pronunciado carácter estacional y fluctuante, ya que se calcula que durante la época vacacional el empleo asciende un 10\% (Lanari et al., 2000).

En ese contexto, una parte de la población local, muy pobre, se dedica al "cartoneo" (derivado de "cartón"), es decir, a la práctica de recolección y venta de los materiales reciclables hallados en los residuos. Se trata de una estrategia de supervivencia que se despliega en el espacio público y que se sitúa entre lo aceptado y lo rechazado por los transeúntes. Por ello, para ser acreditados y poder llevar a cabo su actividad, los cartoneros implementan una serie de tácticas que pueden ser analizadas a la luz de la perspectiva dramatúrgica de Ervin Goffman.

Para llevar a cabo la investigación se realizaron entrevistas en profundidad a cartoneros que transitan por las calles céntricas de la Ciudad

\footnotetext{
${ }^{1}$ La definición de ciudades intermedias (o medias) es bastante compleja y debatida. Tomamos aquí la establecida por UNESCO que señala como tales las de entre 20.000 y 2.000 .000 de habitantes (en Argentina entre 50.000 y 1.000.000), que no sean capitales nacionales y que jueguen un rol importante como centros de referencia para un territorio más o menos inmediato, por ejemplo, en lo social o cultural. (UNESCO, 1999, 42).
} 
de Mar del Plata. Las entrevistas fueron totalmente abiertas y sólo orientadas por un guión que señalaba los temas principales a abordar, pero quedaban abiertas a que aparecieran aspectos que no hubieran sido considerados previamente y que se estimaran significativos. (Taylor; Bodgan, 1987) En cuanto a la cantidad de entrevistas se realizaron las necesarias hasta alcanzar la saturación de información, siguiendo el criterio de Glasser y Strauss de considerar finalizada la muestra cuando se entiende que nuevas entrevistas no agregarían mayor o mejor información (1967).

\section{Sobre cirujas y cartoneros. Breve estado de la cuestión}

Tradicionalmente, en Argentina se llama "cirujas" a las personas que sobreviven de los que recolectan de los residuos revendibles que colectan de los desechos. Se trata de una palabra que data del siglo XIX y que remite a "cirujano", ya que los desechos se extraen de modo similar a como un cirujano extirpa partes de un organismo. Junto con ésta, desde mediados de los '90 y en especial luego del año 2001 - en que se produjo una fuerte crisis social y económica en el país y se expandió la actividad en todas las ciudades- el periodismo consagró el término "cartonero" para denominar al recolector informal $y$, desde entonces, ambas formas se utilizan alternativamente.

La expansión del "cartoneo" mereció la atención de distintos investigadores que analizaron la cuestión desde diferentes perspectivas. A grandes rasgos, puede decirse que existe un grupo que ha abordado el problema en relación con la problemática del trabajo y la construcción de nuevas identidades y otra que se focalizó en el "cirujeo" como vía de recuperación informal de residuos. Dentro del primer grupo, cabe citar el trabajo de Saraví (1994) quien interpretó el fenómeno como una manifestación del trabajo informal. Se trata de un estudio del año 1992, pionero 
en la caracterización de la actividad en la Argentina, que le dedica una parte importante a la definición de la categoría "trabajo informal". Saraví discute con una serie de autores que definen la "informalidad" sólo por su rasgo de "ilegalidad". Es decir, como un conjunto de actividades económicas destinadas a generar ingresos que se producen al margen de todas o algunas de las regulaciones previstas por el Estado. El debate se genera porque, así definida, se incluyen dentro del sector informal toda una serie de actividades que abarcan desde las realizadas por actores con fuerte decisión económica (empresarios, etc.), pasando por las delictivas, hasta aquellas realizadas por las personas en situación de pobreza. De acuerdo con ello, Saraví concluye que deben considerarse otros factores para caracterizar el trabajo informal, tales como la mínima separación entre capital y trabajo, la baja productividad, la escasa inversión de capital, el uso de mano de obra intensiva, el bajo rédito económico y el ser acciones generadas por pobres urbanos con fines de sobrevivencia. Siempre en la línea de las investigaciones centradas en el trabajo, puede citarse el estudio de Corina Aimetta (2009) quien aborda la cuestión de los carreros (quienes circulan con carro a caballo) en un barrio periférico de la ciudad de la Plata, Provincia de Buenos Aires, Argentina. Analiza los sentidos que le dan a la tarea y, centralmente, la tensión existente entre concebirlo como rebusque o como un trabajo, ya que es común y habitualmente detectable entre los investigadores que trabajamos en la temática cartonera, la vacilación de estos sujetos respecto a cómo consideran su actividad, es decir, como un trabajo, una changa, un rebusque o una labor digna y estable (Paiva, 2008; Dimarco, 2005), También, desde esta perspectiva ha trabajado Perelman (2007) quien reafirma este supuesto al decir que, dado que las definiciones de trabajo y rebusque no son universales sino construidas en un contexto histórico determinado, en la etapa cercana al 2001 se visualizan dos tipos de cirujas: "nuevos" y "viejos", es decir, 
aquellos que se incorporaron a la actividad por caída de sus anteriores oficios y los que hicieron siempre la tarea. De acuerdo con ello, para los nuevos, la actividad aparece como un "rebusque", en tanto su horizonte de sentido ubica el "trabajo" en otros oficios ligados a la sociedad salarial, mientras que en los "viejos", las actividades que realizan estuvieron desde siempre en su vida laboral y tienen horarios, clientes y trayectorias que les permiten ubicar su labor como un trabajo (Perelman, 2007, p. 264)

En la línea de los estudios que se han centrado en la problemática de las nuevas identidades surgidas con la crisis de 2001, puede citarse el trabajo de Cross y Gorbán, (2004) que toman como objeto de estudio a piqueteros y cartoneros, y analizan la articulación entre trabajo, identidad política y nuevas formas de acción colectiva implementadas por estos actores sociales. La conclusión del texto, es que, más allá de lo que a priori pudiera suponerse, piqueteros y cartoneros no sostienen visiones disímiles en torno a los valores que asocian al trabajo. Tratándose de grupos pertenecientes a la misma extracción social, sus referencias a un pasado más o menos remoto en donde el trabajo permitía una existencia digna con la cual solventar la propia subsistencia y la del grupo familiar, son similares, lo mismo que su percepción sobre la política y los políticos, a los que desacreditan absolutamente. Ni uno ni otro grupo, depositan en el proyecto político la responsabilidad de mejorar sus condiciones de vida. En todo caso, la única diferencia es que, mientras los cartoneros sólo apelan al ingenio, al esfuerzo personal, y al respaldo familiar, los piqueteros apuestan a que su participación en una organización podrá influir en la dirección que tome dicho proyecto. Pero ello, no tanto porque depositen la confianza en la dirigencia política, si no, más bien porque creen que la fuerza de su propia lucha podrá torcer el rumbo de las decisiones.

Siempre en la línea de la constitución de identidades, Pablo Gutiérrez (2005) realizó un estudio referido a los efectos que tiene la actividad 
del "cirujeo" sobre quienes lo practican. Tratándose de una tarea precaria y realizada con objetivos de mera subsistencia, se trata de sujetos con identidades sociales deterioradas, cuya posición subvaluada proviene, en parte, de sus trayectorias laborales previas ligadas a oficios socialmente valorados y, además, al estigma que supone el trabajo directo con la basura. En rigor, la catalogación que los sujetos hacen de su propia labor oscila entre la descalificación absoluta, pasando por la "pasividad" ante la idea de que "no hay otra opción", hasta la exaltación de aspectos como la "libertad" que otorga la actividad (no hay horarios fijos, no hay patrones), o la "honradez" de realizar esta tarea frente a otras opciones de tipo delictivo. Dicha identidad deteriorada se refuerza con la mirada de los "otros" (vecinos, policías), para quienes la imagen del cartonero oscila entre la compasión y la criminalización del extraño que recorre la ciudad. Por fin, en este trabajo, Gutiérrez concluye que ese estigma no confluyó en una mayor cohesión entre el grupo, y menos aún, en que dicho carácter común haya devenido en la constitución de acciones colectivas para transformar su condición deteriorada material y simbólicamente.

Desde otra línea de interés, un grupo de investigadores ha indagado el fenómeno del cirujeo como una dimensión de la problemática ambiental, y más específicamente, de la Gestión de los Residuos Sólidos Urbanos.

Entre los trabajos producidos, cabe citar el estudio de Cristina Reynals (2002) quien en el año 2002 publicó una ponencia en donde aborda la actividad de recolección y reciclado informal de residuos, dando cuenta de las causas de su expansión durante los '90 y detallando algunas características de la actividad, los de Suárez (2001), quien abordó el rol que ocupan los cirujas como parte del conjunto de actores formales e informales que participan del manejo de los residuos urbanos en los municipios de José C. Paz y Malvinas Argentinas, de la provincia de Buenos Aires, estableciendo las actividades y jerarquías que se establecen 
entre esos eslabones, el de Schamber que realizó una etnografía en la cual explica los pasos y procesos por los cuales la "basura" se convierte en "mercancía" a través de un encadenamiento de cartoneros, depósitos e industrias, que aunque son autónomos, se encuentran interconectados entre sí. (Schamber, 2008). Y, por último, los de Paiva quien analizó las características de los cartoneros que se trasladaban desde el conurbano bonaerense a la ciudad de Buenos Aires en los trenes de línea (2008), como también las diferentes cooperativas de recuperadores que se formaron desde mediados de la década de 1990. Todo ello, interrogándose sobre cuál era el rol de esta actividad en la preservación del ambiente y si era posible referirse a "cuidado ambiental", cuando la labor de los recolectores es de absoluta precariedad, lo que se da de bruces con cualquier idea de ambiente y sustentabilidad. (2004, 2008)

Para cerrar, cabe decir que, ya sea desde la perspectiva del trabajo informal, las identidades, el ambiente o el asociativismo, se han producido una gran cantidad de trabajos que dan cuenta de la situación de las ciudades pequeñas o intermedias tales como San Miguel de Tucumán (2007), Bariloche (2007) Salta (2007) o Córdoba (2009). Sin embargo, existen muy pocos trabajos sobre la situación en la ciudad de Mar del Plata. Sobre ésta, existen muchas crónicas periodísticas, trabajos de extensión y una tesis de grado en elaboración. (Sánchez Reales, 2014) pero no escritos de investigación. Investigar el tema en la ciudad de Mar del Plata resulta importante ya que se trata de una de las ciudades más pobladas del país (5to lugar).

\section{El espacio público. Consideraciones conceptuales}

Suele conferírsele a Habermas la popularización del concepto espacio público en la década del '70. Lo definió como una esfera intermedia entre el estado y la sociedad civil, surgida en el siglo XVIII, en la cual se 
encuentran y se enfrentan las posturas de los distintos actores sociales que conforman la sociedad. Es el espacio social en el que se forma la opinión pública (Habermas, 1989).

Durante la década de 1990 la noción de espacio público fue muy debatida, debido a que se convulsionaron las fronteras tradicionales entre el espacio público y el privado, tanto en su dimensión simbólica como construida. En lo simbólico el avance de los medios de comunicación sobre la vida privada, la aparición de redes sociales que dejan expuesta la vida personal y la expansión de la videopolítica que hace pié en la imagen privada del candidato político y no en sus propuestas de orden público, activaron la producción de muchos estudios sobre estos temas. (Sarlo, 1996; Sennett, 2011; Sarchman, 2013). En lo referido al espacio construido, la privatización de espacios o el cercamiento de sitios públicos que se expandió en la década de los '90 (countries, calles, plazas, barrios privados), como asimismo la mixtura entre nuevos espacios privados y nuevos espacios de sociabilidad (los shoppings, por ejemplo), también movilizaron la escritura de múltiples artículos sobre el tema. (Torres, 2001; Remedi, 2004; Novick, 2004).

Para reseñar los tópicos centrales desde los cuales fue analizado el tema del espacio público, cabe citar un artículo de Soto que establece que el asunto fue abordado centralmente desde cuatro ejes: Individuo grupo; visibilidad- invisibilidad; Interioridad-exterioridad y casa-calle. El primero remite a la división tradicional de Habermas en cuanto a la esfera de los asuntos personales y un ámbito de debate de los asuntos comunes, habitualmente asociado a la política y al estado. El segundo, se centra en las esferas de la vida doméstica, en tanto espacio de la vida de la familia, no competitiva y exenta de luchas por el poder o conflictividades. Por el contrario, la esfera de la visibilidad está asociada al espacio de lo común, del debate público/político o de las relaciones anónimas y no afectivas. 
Siguiendo este razonamiento, el eje interioridad - exterioridad reenvía lo interior a la casa y al ámbito de lo íntimo y lo exterior a lo público y no familiar. Por último, el binomio casa-calle, que también se relaciona con lo íntimo o lo público (Soto, 2009).

En lo relativo a los ejes recién comentados pueden citarse al menos tres trabajos asociados a ellos y que serán útiles para analizar la problemática que nos proponemos. Por un lado, un texto de Carreteiro y Santos (1999), quienes reflexionan sobre los múltiples sentidos que posee la calle para los sectores marginados de una sociedad. Así, por un lado, es un sitio de negociación permanente, ya que la experiencia de la calle se construye por contrato implícito con distintos sujetos, como la policía, los comerciantes, los habitantes y otros grupos. Por otro, es un refugio para muchos sujetos que, por diversas causas, no tienen más que la calle como domicilio (niños abandonados o que huyen de sus hogares, mujeres maltratadas, personas pobres sin techo). Por otro lado, se presenta muchas veces como un recurso de supervivencia, por ejemplo, para aquellos que viven de la recolección de desechos, la apertura de puertas de autos o limpieza de vidrios, vendedores ambulantes y todo tipo de comercio de este estilo. Tanto como ello, es también un lugar de tensión permanente ante el posible ataque de otros sujetos de la ciudad, es territorio de delito y a la vez de contactos mixtos y encuentro entre diferentes. Siempre en la línea de los encuentros y desencuentros que se producen en la ciudad, Perelman y Boy (2010) analizan la situación de los cartoneros que trabajan en la ciudad de Buenos Aires a través del eje visibilidad- invisibilidad, es decir, la necesidad de ser vistos por otros para realizar su trabajo y el deseo paralelo de esconderse debido al estigma que conlleva su tarea. Tal como dicen los autores, muchas veces los cartoneros sienten la necesidad de alejarse de sus barrios para no ser vistos por los allegados, aunque, sin embargo, necesitan ser etiquetados en la ciudad como cartoneros para 
poder obtener una mayor cantidad de residuos revendibles, a partir de los círculos de confianza que generan. El "cliente" necesita poder identificar al cartonero, y el cartonero necesita que el "cliente" lo vea como tal" (ib.2010, p.13). En una línea similar, Wilkis analiza las interacciones en el espacio público de los vendedores de una revista utilizada para la supervivencia de las personas que viven en la calle (Wilkis, 2006).

Para cerrar, es posible citar la noción de espacio público de Erving Goffman, ya que su perspectiva resulta fértil para analizar las situaciones de la vida cotidiana, tal como el caso de los cartoneros en la ciudad. Para este autor, el espacio público se concibe como el mundo de las actividades que se generan mediante la interacción y se organiza mediante normas de coexistencia. Así, presta atención a los aspectos de las interacciones que se destacan cuando las personas se relacionan unas en presencia inmediata con otras. Las relaciones sociales que mantienen los individuos en el marco de la interacción, parecen estar universalmente sometidas a normas de tipo restrictivo y permisivo, por eso, cuando las personas se relacionan de forma regulada con otras, pasan a emplear rutinas o prácticas sociales, es decir adaptaciones estructuradas según las normas. Estas pautas de comportamiento, las rutinas conexas a las normas, constituyen lo que Goffman denomina el "orden social". Siguiendo textualmente al autor: "Lo que me interesa en este volumen son las normas y las ordenaciones conexas de comportamiento relativo a la vida pública: a las personas que coexisten y a los lugares y las ocasiones sociales en que se produce este contacto. Por lo tanto, lo que me interesa en especial es el "orden público" (Goffman, 1971, p.19). 


\section{Cartoneros de la ciudad de Mar del Plata.}

Si bien la práctica del "cirujeo" es muy antigua en la ciudad, lo cierto es que no existen cifras fidedignas sobre la cantidad de personas que se dedican a ella. Sí pueden señalarse algunas características relativas a la tipología de cartoneros. Por un lado, aquellos que circulan en las calles con diversos tipos de medios de locomoción. Por otro, aquellos que recogen residuos directamente en las tierras del basural Monte Terrabusi, ${ }^{2} \mathrm{y}$, desde el año 2004, los recolectores agrupados en la cooperativa CURA (Común Unidad de Recuperadores Argentinos) situada en el predio de disposición final de la basura. Si bien las características de estos recolectores no son las mismas y mucho menos, la calidad sanitaria en la que desarrollan su labor cotidiana (especialmente aquellos agrupados en cooperativa), en este trabajo solamente nos dedicaremos a los cartoneros que recogen con carrito en mano por el centro de la ciudad.

Se trata de personas que oscilan entre los 25 y 60 años, que realizan la tarea desde hace unos 15 ó 20 años y que recurren a ella como estrategia para sobrevivir, en paralelo con otras actividades eventuales, como el trabajo en construcción, el servicio doméstico, el reparto de hielo o la albañilería. Recorren la ciudad durante 7 u 8 horas, todos los días, con carrito a mano, en bicicleta, en moto, en camionetas o carros tirados por caballos y recogen cartón, diarios, botellas, chapa, aluminio, cobre o fierro. El recorrido se realiza en soledad y la recolección de residuos para vender, se alterna con la obtención de alimentos, ropas y muebles que sirvan para la reproducción de la vida cotidiana.

\footnotetext{
${ }^{2}$ El barrio Monte Terrabusi está ubicado en una fracción del barrio Santa Rosa del Mar, en el sur de la ciudad de Mar del Plata. Está situado sobre la Av. Antártida Argentina entre el cementerio municipal y el Predio de Disposición Final de Residuos (Rueda y otros, 2011)
} 
Si bien todos los perciben como una actividad digna, no siempre se encuentran a gusto con la tarea que realizan:

A mi no me gusta esto, yo lo hago por necesidad. Yo te puedo asegurar que mucha gente esto lo hace por necesidad, no porque le guste... (J, entrevista, 21 de marzo 2014).

Para otros en cambio, es una actividad libre y digna, pero siempre que se realice en función de un futuro mejor para los hijos:

...Por un lado soy mi patrón, manejo yo mis tiempos. Y por otro lado tengo beneficios porque lo uso como un objetivo. Algunos lo usan para la bebida, para la droga, yo lo uso para que mis hijos tengan un mejor futuro, no para otra cosa. Soy yo la que está a cargo de esto, mis hijos están por fuera. Mis hijos tienen que estudiar, es el único lema que tengo ( $M$, entrevista, 21 de marzo de 2015)

La recolección se realiza levantando los desechos de los contenedores, de bolsas ubicadas en la vereda o a través de "clientes" que reservan los residuos. Para obtener esta confianza, la "apariencia", la "fachada", resultan fundamentales. En este sentido, vale citar la categoría "actuación" de Goffman quien se refiere a toda actividad de un individuo que tiene lugar durante un período señalado con la presencia continua de observadores, teniendo influencia dicha actividad sobre los mismos. El término "fachada" hace alusión a la dotación expresiva empleada por el individuo durante su actuación. Hay dos tipos de componentes en la fachada personal, por un lado, la "apariencia" y por otro lado, los "modales".

Es necesario que el cartonero trasmita información "acreditable" para otros actores u observadores, como así también, que sostenga ciertos modales que den cuenta de una actitud que sea aceptada en el marco del espacio público. Siguiendo las palabras de un entrevistado:

...mayormente la gente nos tiene como pibes cirujas, es decir, para mi es algo lindo porque me da de comer pero es diferente verme en el carro que verme en una empresa con 
un delantal o con ropa de trabajo. Yo ando en el carrito, ando todo sucio, como que la gente te tiene como más marginado, como que para la sociedad vos sos lo peor, entonces la gente te ve con un carro y te dice cirujita...Como que te discrimina la gente... (D, entrevista, 28 de marzo de 2014).

Para refutar ese estigma y favorecer relaciones estables, es preciso ser cordial, no romper las bolsas y entablar relaciones con vecinos, policías y recolectores formales de desechos. En esta tarea, los "modales", son muy importantes.

Si vos hacés las cosas debidamente no hay problema. Yo lo tengo como un trabajo y no ando por la calle rompiendo bolsas, yo con los basureros no tengo problema porque yo no rompo las bolsas y no llevo cosas que no me sirven. Y con la policía tampoco. Si vos no hacés cosas ilícitas, no tenés ningún problema, no te molestan, no te joden ( $M$, entrevista, 28 de marzo de 2014).

Cuando vos te portas bien la gente te ayuda. Siempre y cuando te portes bien. Ahora si sos medio cachivache, andas fumando porro arriba del carro o tomando vino, no. Yo no te digo que no me fumo un cigarrillo pero trato de no hacerlo delante de la gente que tal vez me da una mano ( $M$, entrevista, 28 de marzo de 2014).

Sin embargo, en otros casos, se vislumbra cómo la persona que "cartonea" tiene dificultades para refutar el estigma, para relacionarse con otros actores de la calle, como así también dificultades para lograr trasmitir una imagen de sí mismo que sea socialmente aceptada.

También están los que cuidan coches. Vos pasas y están con la botellita temprano o con la droga. Entonces... ¿Por qué la gente va a pensar que vos sos bueno y que sos distinto? (C, entrevista, 3 de abril de 2014).

En el caso de Carlos, si bien responde a ciertas normas del espacio público y a comportamientos que son socialmente aceptados, como pue- 
den ser el no drogarse en la calle o no tomar vino, tiene dificultades para relacionarse con otros cartoneros, al punto de no entablar vínculos, así como también describe algunos obstáculos para transitar las calles de la ciudad de Mar del Plata:

No yo no me meto, yo ando solo hago mi trabajo y listo. Soy un bicho especial viste (C, entrevista, 3 de abril de 2014). No porque andan en la droga, en el alcohol (C, entrevista, 3 de abril).

Si por los autos, por los ladrones y por los colectivos tenés que estar esquivando autos todo el tiempo (C, entrevista, 3 de abril de 2014).

En otros relatos de cartoneros de la ciudad de Mar del Plata, se ve lo contrario, en cuanto a la relación a otras personas que practican el "cirujeo" y otros actores que transitan la calle. Incluso se establecen lazos de solidaridad, que son necesarios para lograr vínculos estables:

$Y$ esta bueno, yo conozco un par que andan en el carrito a caballo y la mejor, a veces tengo un montón de mangueadas ¿viste? Y como no me quiero llevar todo a mi casa reparto en el barrio a otros cartoneros (W, entrevista, 3 de abril).

Con todo el mundo soy solidaria, con todo el mundo. Si puedo dar una mano la doy, en ese sentido no soy de tener problemas con nadie. Yo bastante problema tengo con que estoy con el cartón y tengo que ir a buscar las cosas así que te podes imaginar que si me pongo a pelear con todo el mundo y sería un caos mi vida. (M, entrevista, 5 de abril de 2014).

Siguiendo con la descripción de categorías que realiza la teoría de Goffman, podemos analizar como los cartoneros de la ciudad de Mar del Plata, en tanto individuos que transitan el espacio público e interactúan con otros actores, implementan en sus prácticas rutinarias dos papeles básicos que permiten realizar una definición de la persona. Por un lado, se considera a la persona como "actuante", es decir, inquieto forjador de impresiones, empeñado en poner en escena una actuación y también 
como "personaje" - una figura cuyas cualidades, fortalezas y otros atributos deben ser evocados en la actuación-. De esta forma se estructura lo que Goffman señala con el nombre de "si mismo". El "sí mismo", como personaje representado, refiere a un efecto dramático que surge de la puesta en escena del individuo y que tiene lugar en establecimientos sociales. Se trata de implementar un personaje que sea aceptado por otros (Goffman, 2006) Como se señaló en este trabajo el sujeto va a realizar todo lo posible para que esa representación sea aceptada en el marco del espacio público.

En algunos relatos se visualiza como el cartonero espera que los otros le otorguen reconocimiento, lo cual se concreta si utiliza técnicas como el respeto, el saludo rutinario con el posible cliente, etc. El cartonero busca, en este sentido, mantener una imagen que logre ser socialmente aceptada a través de una puesta en escena que le permita la captación del cliente y un reconocimiento en la rutina diaria.

Yo empiezo a saludar o me saludan, me miran y me saludan, yo los saludo yo no tengo drama; Hola como andas?. Buenas tardes. Capaz que solo se suelta la relación, yo por lo menos la gente que me ha ayudado no me puedo quejar porque siempre me han tratado bárbaro. Con respeto como yo trato a las personas que me ayudan ino? Porque ese es el vínculo que uno tiene que tener, el del respeto mutuo es lo principal. (M, entrevista, 5 de abril de 2014).

Vos vas caminando y ya una vez que te conocen te van dando, una vez que te conoce la gente ya vas juntando siempre en los mismos lugares (A, entrevista, 7 de abril de 2014). $Y$ porque yo empiezo a ir y el que me da por ejemplo yo vengo acá (almacén) y me dan yo vengo día por medio y bueno vengo me dan y si tengo que llevar basura la llevo, ya el que me da seguido lo tengo como un cliente y al que no me da nada vengo un par de veces y si no me da nada bueno vengo un par de veces más y si no me da, listo no vengo. (W, entrevista, 3de abril de 2014). 


\section{Reflexiones finales}

Como se ha visto hasta aquí, para los cartoneros como para muchos sujetos en situación de pobreza, el espacio público no es sólo un lugar de tránsito sino un sitio desde el cual obtener los recursos básicos para reproducirse a sí mismos y a su familia (dinero, alimento, ropa).

Para ello, necesitan contraponer al orden público urbanístico y reglamentario (circular, transitar), otro sistema ligado a las actividades de subsistencia (transportar carros, abrir bolsas de desechos, revisar containers o cestos papeleros). Se trata de dos sistemas de circulación diferentes, que en algunas ocasiones conviven de modo pacífico y en otras de manera conflictiva (autos lidiando con carros tirados a caballo en grandes avenidas, dispersión de residuos, etc).

Pero, para poder ser admitidos en el sistema de referencia dominante (urbanístico reglamentario), los cartoneros no sólo deben poner en marcha "rutinas" de recolección "ordenadas, limpias e higiénicas", que puedan coexistir con las que demandan los otros actores de la ciudad (vecinos, recolectores formales, policía), sino también adoptar fachadas que les faciliten la aceptación "social" dentro de la cosmovisión valorativa de dichos sujetos.

Tal como dice Goffman: "La sociedad está organizada sobre el principio de que todo individuo que posee ciertas características sociales, tiene el derecho moral a esperar que los otros lo traten de un modo apropiado" (Goffman, 2006, p.25).Pero debido a la condición estigmatizante de la tarea que realizan, (recolectar basura de la calle) deben implementar fachadas (apariencias y modales) que reconviertan su apariencia desventajosa ante los otros, poniendo en marcha actuaciones que eleven su situación moral.

Para ello, deben, en primera instancia, valorizar su actividad ante sí mismos a través de frases como "lo hago por mis hijos", "el objetivo es 
que ellos estudien" o "peor es robar" y, además, implementar "prácticas defensivas" que reconviertan la mala impresión que pudiera causar su presencia en la calle o su actividad. Así, la vestimenta debe ser lo más apropiada posible (no sucia, ni demasiado desprolija) y los "modales" deben ser los aceptados por los actores fundamentales de la interacción en el espacio público de la ciudad. De acuerdo con ello, no fumar marihuana, no tener conflictos ni peleas con nadie, no dispersar desechos y llevar sólo lo que se necesita, son parte de las pautas de conducta que permiten ser aceptados en el orden moral de la sociedad general.

Luego de la recolección en la ciudad, los cartoneros realizarán la separación de los desechos en sus casas para transportar los residuos ya clasificados a los diferentes depósitos de compraventa que existen en la ciudad de Mar del Plata. ${ }^{3}$ En esa instancia, deberán poner en marcha otra serie de acciones de aceptación tanto físicas (llevar el material ordenado, clasificado, no mojado), como mostrar fidelidad al dueño del depósito al que le venden o de aceptación de las pautas de pago que le impone el dueño del local de compraventa, para poder sostener en el tiempo esta actividad de subsistencia necesaria para reproducir su existencia cotidiana.

Verónica Paiva: Lic en Sociología (UBA) y Doctora en Ciencias Sociales UBA). UBA-UNMdP- Fitz Roy 2476, piso 8, depto D (1425). Ciudad de Buenos Aires. Argentina. \vtpaiva@gmail.com

Juan Banfi: Estudiante de Sociología. UNMdP. Funes 3350-Mar del Plata, Argentina (7600). TE: - $\backslash$ banfijuanignacio@hotmail.com

\footnotetext{
${ }^{3}$ Según estimaciones, existen cerca de 60 depósitos de compraventa de desechos en la ciudad. ("En Mar del Plata trabajan unos 1900 cartoneros" en lo que pasa.net, 29/10/2012. http:// www.loquepasa.net/web/?p=3910)
} 


\section{Referencias}

1. AIMETTA, C. ¿Salir a carrear. Trabajo o rebusque? Indagaciones sobre el trabajo, la cultura y las prácticas políticas en sociedades segmentadas. Trabajo y Sociedad, 12, 2009. Disponible en: http://www.scielo.org.ar/scielo.php?script=sci_artt ext\&pid=S1514-6871200900010000. Acceso en: 5 mar 2015

2. BECCARIA, L. Empleo e Integración Social. Buenos Aires: Fondo de Cultura Económica, 2001

3. CROSS, C.; GORBÁN, D. Otra vez en la vía: Cartoneros y Piqueteros en las calles Argentina. In GALAFASSI, Guido y LENGUITA, Paula (comps), Nuevas Prácticas Políticas en la Argentina, 2004. pp 149-180. Disponible en: http://www. insumisos.com/lecturasinsumisas/Nuevas\%20practicas $\% 20$ politicas $\% 20$ en $\% 20$ America\%20Latina.pdf. Acceso en: 6 abril 2014

4. DIMARCO, S. Experiencias de autoorganización en cartoneros: un acercamiento a la configuración de vínculos laborales, sociales y políticos en contextos de exclusión social. Informe final del concurso: Partidos, movimientos y alternativas políticas en América Latina y el Caribe. Programa Regional de Becas CLACSO, 2005 Disponible en: http://biblioteca.clacso.edu.ar/ar/libros/becas/2005/partijov/ dimarco.pdf. Acceso en: 7 marzo 2014

5. GLASSER, B.; STRAUSS, A. The discovery of Grounded Theory: Strategies for qualitative research. Aldine: Nueva York, 1967.

6. GOFFMAN, E. Relaciones en público. Microestudios de orden público. Madrid: Alianza editorial, 1971

7. GOFFMAN, E. La presentación de la persona en la vida cotidiana, Buenos Aires: Amorrortu, 2006

8. HABERMAS, J. The Structural Transformation of the Public Sphere. Massachussets: MIT Press, Cambridge, 1989

9. LANARI, M., LÓPEZ, M.; ALEGRE, P. Empleo en Mar del Plata. Restricciones y oportunidades. Análisis del mercado de trabajo local en el contexto de la evolución nacional. In: Faces, Año 6, N 9, 23-46 septiembre-diciembre. Facultad de Ciencias Económicas Universidad Nacional de Mar del Plata Disponible en: http://nulan.mdp.edu.ar/64/\#.VK2jWNKG81I Acceso en: 9 abril 2014

10. PAIVA, V. Las cooperativas de recuperadores y la gestión de residuos sólidos urbanos en el área metropolitana de Buenos Aires. 2003. In: Theomai. Estudios sobre sociedad, naturaleza y desarrollo, número especial, 2004 Disponible en: http://revistatheomai.unq.edu.ar/numespecial2004/artpaivanumespec2004.ht Acceso en: 4 marzo 2015 
Sociologias, Porto Alegre, ano 18, no 41, jan/abr 2016, p. 270-290

11. PAIVA, V. Cartoneros y cooperativas de recuperadores. Una mirada sobre la recolección informal de residuos. Buenos Aires: Prometeo, 2008

12. PERELMAN, M. ¿Rebusque o trabajo? Un análisis a partir de las transformaciones del cirujeo en la ciudad de Buenos Aires. In: SCHAMBER, P.; SUÁREZ, F. (comps); Recicloscopio. Miradas sobre recuperadores urbanos de residuos en América Latina. Polvorines: UNGA-UNLA-Prometeo, 2007, pp. 245-267

13. PERELMAN, M.; BOY Martín. Cartoneros en Buenos Aires: nuevas modalidades de encuentro. In: Revista Mexicana de Sociología, v.72 n.3, pp. 15-27, México jul./sep, 2010

14. REMEDI, G. La ciudad latinoamericana SA (o el asalto al espacio público). In: NOVICK, A. (ed); Las dimensiones del espacio público. Problemas y proyectos. Buenos Aires: Gobierno de la Ciudad de Buenos Aires, 2004, pp.15-25

15. REYNALS, C. De Cartoneros a Recuperadores Urbanos. Ponencia presentada a Respuestas de la Sociedad Civil a la Emergencia Social: Brasil y Argentina comparten experiencias. Seminario Internacional realizado por el Postgrado en Organizaciones sin Fines de Lucro y el Centro de Emprendorismo Social e Administração em Terceiro Sector, Facultad de Economia, Administração e Contabilidade, Universidad de San Pablo, Brasil, 2002. Disponible en: http://lasociedadcivil.org/uploads/ciberteca/reynals.pdf. Acceso en: 4 marzo 2015

16. RUEDA, F. Asesoramiento técnico a emprendimientos productivos del barrio Monte Terrabusi. Ponencia presentada al XI Congreso Iberoamericano de Extensión Universitaria, Santa Fe, UNL, 2011. Disponible en: http://www.unl.edu. ar/iberoextension/dvd/archivos/ponencias/mesa1/asesoramiento-tecnico-a-empr. pdf. Acceso en: 5/3/2015.

17. SÁNCHEZ REALES, X. Cooperativa CURA (Común Unidad de Recuperadores Argentinos), (tesis para licenciatura en Sociología, en elaboración). Facultad de Humanidades, UNMdP., 2014.

18. SARCHMAN, I. Facebook y el declive del hombre privado. Una aproximación a los nuevos modos de construcción autobiográfica, Ciencias Sociales, revista de la Facultad de Ciencias Sociales N 83, mayo 2013, pp.73-79.

19. SENNETT, R. El declive del hombre público. Barcelona: Anagrama, 2011

20. SOTO, P. Lo público y lo privado en la ciudad, Casa del Tiempo, Vol II, Época IV, N 17, México, UAM, marzo, 2009, pp. 54-58

21. SUÁREZ, F. Actores Sociales de la Gestión de Residuos Sólidos en los Partidos de Malvinas Argentinas y José C. Paz. Disertación. (Tesis de maestría) Facultad de Filosofía y Letras, Universidad de Buenos Aires, 2001. 
22. SCHAMBER, P. De los desechos a las mercancías. Una etnografía de los cartoneros, Buenos Aires: SB, 2008.

23. TAYLOR, S.; BODGAN, R. Introducción a los métodos cualitativos de investigación. Buenos Aires: Paidós, 1987.

24. TORRES, H. Cambios socioterritoriales en Buenos Aires durante la década de 1990, EURE, 27(80), 2001, pp 33-56.

25. UNESCO. Ciudades intermedias y urbanización mundial. Disponible en: http://www.unesco.org/most/ciudades.pdf) Acceso en: 10/12/2014.

26. WILKIS, A. Las dimensiones expresivas y morales del orden de la interacción en el análisis de la venta de las publicaciones de la calle. Una aproximación desde la sociología de Ervin Goffman. Campos 7, 2006, pp. 53-70.

\section{Entrevistas citadas}

J, entrevista en la calle, Zona céntrica de la ciudad de Mar del Plata, $21 / 3 / 2014$

M, entrevista en la calle, Zona céntrica de la ciudad de Mar del Plata, $21 / 3 / 2014$

D, entrevista en la calle, Zona céntrica de la ciudad de Mar del Plata, 28/3/2014

Ma, entrevista en la calle, Zona céntrica de la ciudad de Mar del Plata, $28 / 3 / 2014$

C, entrevista en la calle, Zona céntrica de la ciudad de Mar del Plata, $3 / 4 / 2014$

W, entrevista en la calle, Zona céntrica de la ciudad de Mar del Plata, $3 / 4 / 2014$

Mo, entrevista en la calle, Zona céntrica de la ciudad de Mar del Plata, $5 / 4 / 2014$

A, entrevista en la calle, Zona céntrica de la ciudad de Mar del Plata, $7 / 4 / 2014$

Recebido em: 05/03/2015

Aceite final em: 03/06/2015 